\title{
Incorporating a Critical Pedagogy of Place in the Mathematics Classroom: Rural School Bussing
}

\author{
Jim Gleason \\ The University of Alabama \\ Johnny Belcher \\ Pikeville High School \\ Deborah Britt \\ Ohio University \\ Paula Savich \\ Mayland Community College
}

\begin{abstract}
There is a growing consensus within the mathematics education community that what students of mathematics ought to learn should connect with real world examples from their lives and culture. Based upon a group project in a discrete mathematics course, issues involved in rural bus routing, including social, political, economical, and mathematical issues are described in this paper. Several suggestions for incorporating a study of rural school bussing into the mathematics classroom at various levels from kindergarten to post-secondary are included.
\end{abstract}

\section{Introduction}

According to Dewey (1916), one of the primary goals of education in the United States is to prepare students to be active and engaged citizens in our democratic society. To achieve the goal of preparing citizens, we must not ignore the cultural, economic, and political societies with which the students have been involved and will engage in the future. Instead, we need to incorporate the issues of the students' cultures into the classroom using ideas from critical theory and place-based education (Gruenewald, 2003).

Jim Gleason is an assistant professor of Mathematics Education in the Department of Mathematics at The University of Alabama.

Johnny Belcher is a doctoral candidate with the Appalachian Collaborative Center for Learning, Assessment, and Instruction in Mathematics, and is a high school teacher in Pikeville, Kentucky

Deborah Brit is a doctoral candidate with the Appalachian Collaborative Center for Learning, Assessment, and Instruction in Mathematics, and former high school teacher of 29 years.

Paula Savich is a doctoral candidate with the Appalachian Collaborative Center for Learning, Assessment, and Instruction in Mathematics, and is a mathematics instructor at Mayland Community College. 
While this incorporation of the students' culture has occurred almost universally in subjects such as philosophy, political science, and education, and is starting to make more of an impact in biology and chemistry, incorporation of these traditions into the mathematics classroom has not happened so prevalently. However, with the evolution of our society towards a culture of technology and quantitative information, it is becoming more important for students to address issues that can be interpreted mathematically. Teachers must be encouraged to include these social, cultural, economic, and political issues in the mathematics classroom.

One example of a social issue that is mathematical that can involve ideas from critical pedagogy is student debt. Other issues that could arise in the mathematics classroom include probability and gaming theory, connecting to the real world (e.g., lotteries); the amortization tables for home loans; and how companies and individuals use statistics to argue various positions regarding social issues. For students living in a city, one can also teach about different ways of measuring distance using the "taxi cab metric", which is based on measuring distances between two places in a city where the streets are laid out in a grid pattern. If the students live near the ocean, one can show how to model the tide using periodic functions. Schools with large populations of immigrant students can focus on currency exchange rates from the various countries of origin.

While many other examples exist and are on the internet and in textbooks, rural America is rarely represented. Some of the mathematical issues currently affecting rural communities are the rate at which people are leaving a region, the economics of running a small family farm versus a large corporate farm, and how environmental decisions affect the community.

One of the biggest issues for rural communities involves the effect of school consolidation on the education of their children. How the issue of rural school consolidation arose in a graduate discrete mathematics class through a group project studying rural school bus routes will be discussed in this article.

\section{School Consolidation}

It is the separation of schools from homes that is literally and metaphorically represented in long bus routes. Mathews (1996) asks the question: "Is there a public for public schools?” Mathews writes:

Unhappily, many Americans no longer believe the public schools are their schools, and yet this isn't a major issue today. On the contrary, all kinds of school reorganization go on with little regard for the effect on the relationship between the public and its schools. However, reasonable in their own right, market-based reforms, court decrees, increased financial control by state governments, and professionally set standards may be putting citizens at an even greater distance from the public schools. That is the most alarming implication of more than ten years of research commissioned by the Kettering Foundation on the relationship between the public and its schools. (p. 2)

Separating the public from its schools is being carried out quite effectively in rural locales where physical distance is lengthened by consolidation. This physical distance from the students to the school dictates that a larger percentage 
of students must depend on district provided transportation and are less likely to participate in extra-curricular activities due to a large portion of their day already committed to traveling to and from school. This decrease in extra-curricular activities is further complicated by the values of rural populations.

Tonnies (1887/1957) recognized a contrasting sociological phenomenon among agrarian societies and the newly emerging industrial societies of the late 1800s. He purported these two societies differed in culture values and named their differing orientations Gemeinschaft and Gesellschaft. A group of people connected by common threads such as daily work or beliefs characterizes a Gemeinschaft community. These Gemeinschaft communities develop a sense of interdependence for one another. This is quite different in a Gesellschaft community where ties between members are loose and common threads are few. Each individual operates primarily for self-interest as a free agent might in a capitalistic society.

Woodrum (2004) found Gemeinschaft views were held by poor Appalachian families in a Southeastern Ohio school district. For these Appalachian families, the school operated by gesellschaft values educating their children to be citizens in a socially mobile culture that deemphasizes place and local values (Woodrum, 2004). Long bus routes are another example of the disconnection between schools and rural communities. Instead of making the school more accessible, the results of consolidation create circumstances that reduce accessibility.

This disconnection, due to consolidation, becomes critical when considering Peshkin (1978), who found the school to be the "hub" of the community. Durkheim (1961) coins the term "mechanical solidarity," meaning the social glue that binds society together in the form of a collective conscious. For Durkheim, the community serves to provide mechanical solidarity. A combined theory of Durkheim and Peshkin would allow us to state that the school as the hub of the community provides mechanical solidarity. However, in an educational system where federal and state agencies provide funding and consolidate schools for "efficiency," rural schools find themselves paying more attention to generic reform than the local needs of the community they serve. Long bus routes are a structure that serves to further tear down Gemeinschaft views so commonly cherished by rural communities.

School consolidation also affects rural communities economically. Using data from the 1990 US Census and the New York State Department of Education, Lyson (2002) identified community-level characteristics associated with the presence or absence of a school. Considering rural communities with populations less than 500 and from 501 to 2500, he found that social and economic welfare was higher in all rural communities where a school existed. Further, the absence of a school economically affected the smallest villages with even fewer resources. Lyson concludes: "The money that might be saved through consolidation could be forfeited in lost taxes, declining property values and lost businesses” (p. 135).

If the goal of consolidation is to improve the level of education that students receive, particularly in rural areas, the results are far less clear (Howley \& Howley, 2004). Assumptions behind consolidation are economic in nature as Theobald and Nachtigal (1995) describe the argument that: "If our cities and factories are growing larger, so must our schools” (p.132). Large consolidated 
high schools require a more specialized nature for the work, so the day-to-day power and control of education passes from the local community to professionals and to the state (Woodrum, 2004) as consolidations occur.

When consolidations occur, the social context also changes, which may be the reason that most proposals to close schools continue to elicit resistance by citizens (DeYoung \& Howley, 1992). DeYoung's (1995) account of the demise of a rural high school due to consolidations is an ethnographic example of local resistance. The account is significant as a rich description of the typical pattern of resistance that emerges in rural communities when consolidation occurs.

\section{School Bussing in the Rural Environment}

Riding the bus to school has a long tradition in the United States that began with riding in horse drawn carts. For many students, school bussing is not an option, particularly in rural areas (Chen, 1990). In rural regions, school bussing is an issue that has an impact, not only on student achievement, but also on the culture as a whole, with some students spending as much as six hours per day on a bus (Fox, 1996).

Since 1920, as the number of school districts has shrunk from 120,000 to less than 15,000 the percentage of students bussed to school has grown from $10 \%$ to almost 60\% (Spence, 2000b). In the United States, 60\% of all schoolchildren ride a bus to and from school with the annual cost of the system being over $\$ 10$ billion (Zars, 1998). Where rural districts spend upwards of 6-8 percent of their budget on transporting students, non-rural districts spend approximately 4 percent (Killeen \& Sipple, 2000). West Virginia, a largely rural state, spends more of its education dollars on transportation than any other state, nearly 7 percent of its education budget, with four West Virginia counties spending more than 10 percent of their budgets on bussing (Reeves, 2003).

While there is a significant amount of research on school size and school consolidation in general, the research on the effects of school bussing because of school consolidation is limited. This issue was significant enough for a Rural Educators group to meet in December 1998 and create “An Agenda for Studying Rural School Busing” (Howley, 2000). The research that does exist usually falls into one of four major categories; the impact of bussing on student achievement, the social and political impact of bussing on schools and communities, and the economic impact of school bussing.

The educational research on the impact of bussing on student achievement is particularly scarce, and what research does exist is inconclusive. The primary articles that found school bussing to have a negative effect on student achievement are articles by Lu and Tweeten (1973), and Herbst and Herczyński (2005). On the other hand, research by Zoloth (1976) and Floyd (1983), using similar methods to $\mathrm{Lu}$ and Tweeten, found that bussing does not have a significant impact on student achievement.

The issues of long bus rides and school consolidation are intimately connected. Through consolidation, children travel by bus from communities that lose schools, sometimes a considerable distance from home. Students affected the most by consolidation, usually rural lower income students, lose not only their local schools, but now have to relinquish family and community time to ride on longer bus routes. 
Howley (1996) writes that school consolidation has a particularly deleterious effect in low SES districts. Howley (2001) studied school bus rides in Arkansas, Georgia, New Mexico, Pennsylvania, and Washington and found that in $85 \%$ of rural school districts students experienced bus rides exceeding 30 minutes, the generally agreed upon standard for the maximum length bus ride for elementary students. He also reported that $100 \%$ of rural districts had mixed ages on at least some school buses-a practice that many educators discourage. Poor rural students confront longer bus rides than their more affluent peers, and the bus rides experienced by rural children are more likely to be over rough or even mountainous roads (Howley \& Howley, 2001). Howley, Howley, and Shamblen (2001) report that principals believe that long bus rides have a negative impact on parental involvement in schools. Rural schools are less likely to have a full time bus supervisor and rural districts are more likely to have mixed age level students on the bus (high school, middle school and elementary) (Howley \& Howley).

Looking at parents' perceptions of the impact of long bus rides, Ramage and Howley (2003) found parents' three major concerns were atmosphere on the bus, length of ride, and safety. In two different articles in 2000, Spence looked at the effect of long bus rides in West Virginia, the state that spends the largest proportion of its education budget on transportation, where parents were concerned that long bus rides cut into family time and made it difficult for students to participate in sports and other after school activities (Spence 2000a, 2000b). Fox (1996) found that the time constraint of traveling long distances to school has an effect on the number and type of activities that students participate in, relationships with other students, the number and type of activities family members participate in, and the overall perception of education. Because of these types of concerns, Zars (1998) called for research on the impact of bussing on student achievement, on family life and school budgets. Studies of the influence of length of bus ride are necessary; particularly the relationship of long rides to student achievement or more broadly with school performance in all areas (Howley \& Howley, 2001).

Killeen and Sipple (2000) look at bussing as one of the hidden costs of school consolidation since one of the main arguments in favour of school consolidation is "economy of scale". However, most decisions do not factor in the time children spend on the bus into the economic impact of bussing. They also point out that rural school districts devote over $4 \%-8 \%$ of their annual budgets to transportation, versus about $2.5 \%$ for urban districts. Since more money is spent on transportation, less money is available for instruction. Reeves (2003) placed the disproportionate amount that rural districts spend on transportation into the context of No Child Left Behind. Money spent on transportation is money not used to meet Adequate Yearly Progress goals.

In a study of a school system in Webster County, West Virginia, parents stated, "There's not going to be any family value if you don't have any time to spend with your family" (Spence, 2000). Howley (2000) agrees that bussing might constitute a costly intrusion into family and community life, especially when it involves long rides. Another Webster County mother whose daughter attended the consolidated Webster County High School estimated that from the time her daughter left home in the morning until she returned in the afternoon, she had spent $32 \%$ of her time on a school bus. One Webster parent said her 
daughter calculated her bus experience a different way. She figured out that traveling to and from the high school for four years, she went more than the distance around the world two times. That does not count the times she came home and went back to games, just morning and evening routes associated with regular attendance (Spence, 2000).

The results of these studies show that school bussing is an important issue, particularly in rural regions. Therefore, the issues involved in rural school bussing must be included somewhere in the curriculum of rural schools. Since many of the issues involved in bus routing are mathematical, the mathematics classroom is an appropriate environment in which to address them.

\section{The Mathematics of School Bussing}

While many different computer programs exist to determine optimal bus routes, including some for rural regions, the mathematics involved is generally the same. (See Chen, 1990; Corberan, 2002; Messer, 1998; Nygard, 1982; Rhoulac, 2000.) Each of these systems represent bus routes with a graph consisting of a finite number of vertices (also known as nodes) and a finite number of edges, each edge paired with two vertices. Then various algorithms are employed (some of which we discuss below) to calculate optimal solutions. Figure 1 is an example of such a representation containing 8 vertices and 12 edges.

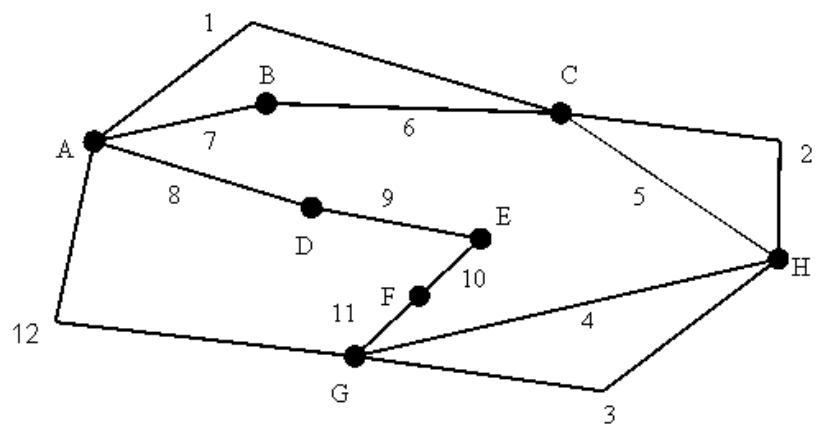

Figure 1. Sample Weighted Graph.

The simplest rural county scenario typically consists of one high school and middle school with several elementary feeder schools. Schools' locations are due to geographical considerations that may date back some time in the history of the county. In most rural districts, all age levels ride the same bus due to the number of buses needed to travel duplicate routes. Commonly, districts bus students who are of high or middle school age from their homes to the closest elementary school and then transfer to another bus to travel to the more centrally located middle or high school. Thus, bussing students from home to their local elementary school is the first task in planning routes.

To start this task, Dijkstra's Shortest Path Algorithm can be employed to find the shortest path between vertices (e.g., elementary school, beginning and ending points of similar road segments). Each link (edge) is assigned a comparison weight to indicate which path is preferable. (For more information about Dijkstra's algorithm, see pp. 184-186 of Wheeler and Brawner (2005) or pp. 106- 
107 of Chartrand and Oellermann (1993).) Though it would seem logical to weight each segment of road in the elementary district by mileage, with school bussing, both time and mileage need minimizing. This phenomenon is similar to the brachistochrone problem posed by Johann Bernoulli in 1696 and solved by Newton and others in 1697 using the calculus of variations, which is used to study the fastest route for a ball to roll from one point to another lower point with just the force of gravity. The similarity between the brachistochrone problem and rural bus routing is that the solution is not the path with shortest distance (Dunham, 1991).

In 2000, Rhoulac, Rhoupail, and Tsai cited one of the weaknesses of North Carolina's Transportation Information Management System (TIMS) as having no algorithms to accurately estimate travel time for a link. In Rhoulac and colleagues' extensive study of how to improve predictions of travel time it was found, "The two most important contributors to the travel time of a school bus on a link are 1) traffic and roadway conditions and 2) student loading” (p. 17). Drawing from one author's experience with driving a school bus in mountainous areas, it was a concern that uphill road grades and road quality, such as lane width, number of lanes, and road surface, affect bus travel times extensively. Though mountainous terrain does not always describe rural areas, in the Appalachians where this study took place, it is the norm. Rhoulac's study focused on several regions in North Carolina but excluded the western portion of the state, which includes mountainous terrain, a weakness Rhoulac recognizes.

Once a plan is established for all children to get to the elementary school, planning the shortest path to the middle and high school from each elementary school follows. One can use Dijkstra's Algorithm to find the shortest path from each elementary school to the middle and high school as well. Whether the bus reached the middle or high school first would not matter since each bus would be traveling to both. After carrying out Dijkstra's Algorithm from each elementary school, Figure 2 represents the paths in combination that buses would be traveling from each elementary.

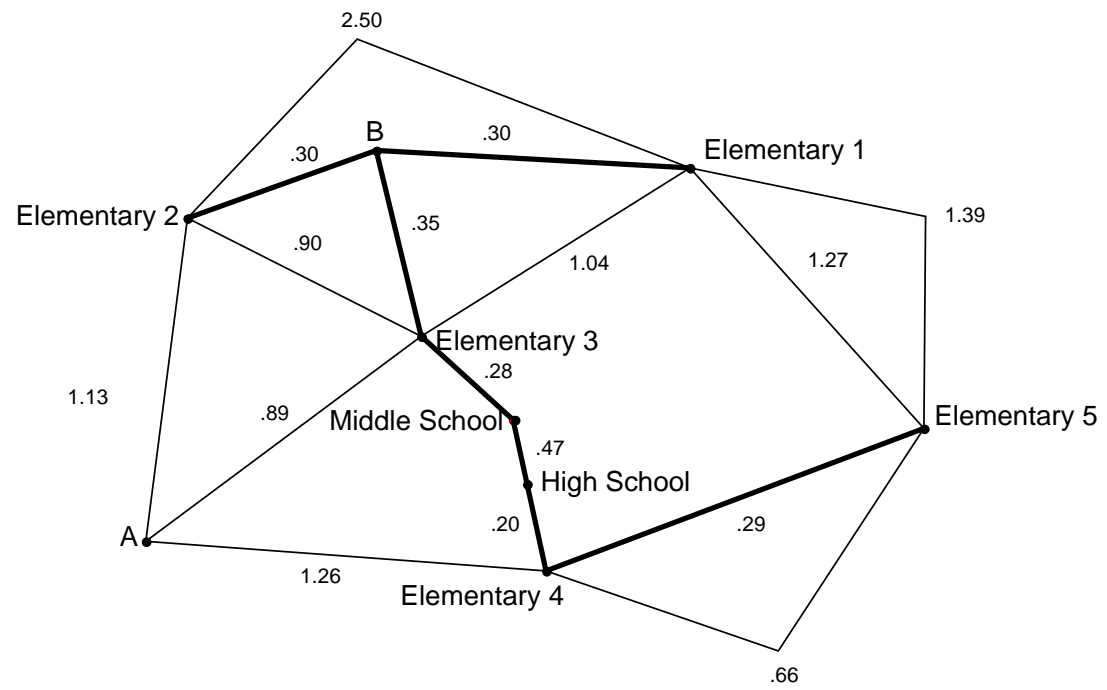

Figure 2. Weighted School Bus Route Graph. 
Even though these paths resulted from Dijkstra's Algorithm, what exists as a result when viewed in this manner is a minimal spanning tree. A spanning tree is a connected graph with no cycles with each vertex included (vertex meaning each school). A connected graph means that for any two vertices, there exists a path between them. A cycle is when there are two unique paths between two vertices. This combined path graph is a spanning tree where the elementary, middle and high schools are vertices of the tree.

Prim defined an algorithm for finding the minimal spanning tree of a connected graph. (See Chartrand and Oellermann (1993), pp. 91-92, for further discussion of Prim's Algorithm.) So the combined weight of all the sections of road that make-up the tree is the least of any other possible combinations in the larger graph. Therefore, buses are running the least weighted roads in combination, which would optimize overall time on the road.

The initial step in Prim's Algorithm is to find a section of road that has the least weight and select the road and its vertices (the link containing the high school and elementary 4). In the first iteration, we look for sections of road adjacent to the original section that has the least weight and select it and its vertices (the link containing elementary 4 and 5). The algorithm continues until it selects all vertices with $n-1$ sections of road, where $n$ equals the number of vertices. This method serves as an alternative approach to finding the express route skeleton that contains the least weight of combined routes and still reaches all elementary schools.

\section{Incorporating School Bussing Into a Graduate Level Discrete Mathematics Course}

In the spring of 2005, the authors, one as the instructor and the others as students, participated in a graduate level discrete mathematics course designed for teachers. The only instructions given to the students were that the final presentation of the project should be professional as if hired to complete the project; the project must incorporate several ideas from the course; and the project and presentation must be creative. The lack of information about the projects was intentional in order to give the students the experience of creating classroom projects as well as determining what type of project is possible to complete in a fixed amount of time.

Another result of the flexibility of the projects was the creativity and diversity of the final projects. The project that this article focuses on came about because of a course that the students had recently completed in rural education as well as the rural background of the students involved in the project. Throughout the semester, the path of communication between the students and the instructor was open and a large amount of learning took place for all involved: the instructor dealing with the rural issues and the students with the mathematics.

The group first chose a school district in rural North Carolina to focus their attention and to explore the bus routing used in that district. They contacted the transportation director at the school district and found that the State of North Carolina mandates the computer program that all districts in the state must use, whether urban or rural. They also discovered that a majority of those who use the program do not understand the mathematics behind the software and accomplish their goals only through a process of trial and error. 
From further explorations, it was evident that this particular rural mountainous region had unique characteristics causing difficulties in standard bus routing algorithms. These included some roads that were not safe for a school bus, excessively long travel times for rural students, and difficulties estimating the time necessary for a bus to travel on certain roads. Realizing that other rural areas may also have different unique characteristics, a basic study of the algorithms used for bussing our nation's children seemed necessary.

The group chose to focus on one elementary school district and to create a revision of the routing for that school. They followed with an exploration of the roads of that district and creation of a weighted graph that incorporated road conditions as well as speed limits and number of children on each road. Using this weighted graph, the group created bus routes with the stipulation that no child would be on the bus longer than 60 minutes.

The group did not have access to the addresses of the children in the elementary school district. What they did know was approximately the number of children bussed to school and the density of the dwellings in the district, both from driving the roads and from studying aerial photographs. They also knew that some students lived in coves where the road ended, thus a school bus driver would have no choice but to turn around and retrace the route. Although the bus routes in this project were hypothetical, the group deemed them realistic based on their experience as residents and teachers in rural mountain communities, their experiences riding the bus as children and their experience as parents of children who ride the bus today.

After completing the work on the elementary school district, the group focused their attention on getting the middle and high school students to their schools. In addressing this problem, the group adopted a protocol that bussed all students to the closest elementary school, followed by a redistribution of the older students for travel to the appropriate middle or high school.

After making this decision, the group used Dijkstra's algorithm to find the shortest distance from each elementary school to the middle school and high school. They then subtracted the amount of time to cover the distance from the amount of time allowed to transport students to each of these elementary schools. They repeated the process using Prim's algorithm to find minimal spanning trees with the result being the same. Through this process, the group reduced all students ride times to below 60 minutes while only increasing the number of buses by one.

The group also put together an oral presentation for the class that involved video interviews with parents in the district, pictures of the road conditions that the buses travel on that contributes to the time on the bus, and an explanation of what they found and how their solution helps to solve the problem.

Through this project, both the instructor and the students learned more about the issue of school consolidation and the problems of rural school bussing that results. This motivated all involved to begin making changes that would create long-term solutions to the problem. This article serves as a manifestation of the desire to help others to incorporate these ideas into the classroom and begin the discussion in their regions. 


\section{Incorporating the Mathematics of School Bussing Into Other Classroom Situations}

A graduate course composed of primarily teachers is a good place to begin discussing issues involving school bussing. However, needed change will occur with rural school bussing only when the entire community knows that options exist and demand a change. Educating school administrators, teachers, and most importantly, the general population of a community is a necessary first step.

The most efficient way to educate the general population about rural school bussing is to teach about the issues in the schools. While the primary objective will be the learning of mathematics and the primary audience will be the students, the parents will also learn about the issues through helping their children with homework, with group projects, and by answering their children's questions resulting from the discussion in the classroom.

The main difficulty with incorporating the issues of rural school bussing into the mathematics classroom across the curriculum is that most of the mathematics involved in school bussing occurs primarily in the post-secondary environment. However, many of the issues, with minor modification provide meaningful context for current mathematics curriculum objectives at all grade levels.

\section{Pre-Kindergarten to Grade 2}

One of the primary concepts in rural school bussing is how to measure distances. While distance between two places is usually measured in units such as miles or kilometres, it is often more practical and useful to measure the distance in units of time. For children in the lower elementary grades this is particularly true since time measurement is easier to grasp. In rural regions, this difficulty in measuring distance and time is often due to road conditions that include unpaved and mountainous ones.

One way to incorporate the measurement of distance with regard to time into the classroom is to have each student measure the distance traveled to and from school in minutes. The students can use this information to create a graph detailing the data. With teacher provided data, students can also compare the distances traveled and determine the longest and shortest trips.

The students compare this information with the average amount of time spent travelling to school in various regions or compare their commuting time with the average commute of adults in their region or in another region. (The U.S. Census Bureau reports this information on their web site at http://www.factfinder.census.gov.) A discussion would follow as to why their commute is longer than the average commuting time of 25 minutes among adults in the United States (U.S. Census Bureau, 2006). The discussion would then lead to exploring the implications related the priorities of society regarding the value of various individuals' time.

Another option is to have the students talk about how they spend their time on the bus and how they could use this time differently if they had a shorter commute. The discussion might include having more time for homework, family chores, or playing games. The teacher could then direct the discussion to how a shorter commute might give other students an advantage academically. It would also be appropriate to discuss what changes they can make to their travel time to 
make it more productive and to reduce the advantage of those with shorter commutes.

\section{Grades 3-5}

In the latter elementary school years, students can also begin to explore the relationship between the amount of time and miles between places. By collecting data on both the distance and time to and from school, they can look for relationships between these two quantities. They can also use simple conversions to convert minutes into hours, or fractions of hours, and use this information to compute the average speed on the trips.

This lesson can lead to discussions on why different students have various average speeds. Some of the contributing factors will be road conditions, the number of students picked up along the bus route, and the ability to travel on a well-maintained highway for part of the trip.

Estimated time per stop is another excellent class activity, if access to a bus and driver willing to aid in the experiment is available. Experimenting with students of various ages, the students can take time measurements and average them for different numbers of students per stop and number of stops per link. For safety reasons, one may conduct the time trials in the parking lot instead of on the road.

While the students are studying the length of time per stop, the students can also study where the stops are located. This study would include looking at how these locations and the number of bus stops might lead to longer or shorter commuting times. The students should also study the location of the bus stops from a safety perspective. This would include whether rural students bus stop locations are more dangerous than suburban locations due to vehicles traveling at faster speeds along narrow, curvy, or non-maintained roads.

Each of these studies could lead to having the students write letters to their local newspaper to inform the community about what they have found. The students could also write letters to the transportation director of their school district to offer suggestions for change. However, the greatest change might occur if the students invite the members of the local board of education to spend a week commuting with them. If done, these influential members of the community would have a better understanding of the transportation issues affecting the students in their district.

\section{Grades 6-8}

During these years, the students can begin to work with graphs and networks to discuss the school bus problem. After collecting information about where students live and the roads traveled to get to school, have the students create network graphs using this information. The students then can find a route that connects all of the houses with the least amount of backtracking.

The exploration of paths in rural bus routes expose differences that exist in urban routes. Paths in rural locations are typically terminal or end resulting in the bus retracing its original path just in the opposite direction. Urban road systems can form loops in their paths due to turning around the block or the absence of physical barriers such as mountains. In states that mandate one size fits all 
software for optimizing bus routes, students could advocate change through communications with the state transportation cabinet. These communications could manifest themselves through letters, videos, student presentations, etc. in which the arguments depend upon mathematical justifications.

Following a comparison of the students' routes with the current routes, the students can discuss possible reasons for the differences. These differences in routes may include time limitations, accounting for students in other classes at the school who ride the same bus, and the number of buses available. The students can look at the length of time that they would travel on their proposed routes and compare that to the amount of time they currently spend on the bus.

Using the information obtained completing the project, the students can work together to create a professional proposal to send to the district office in hopes of making changes to the routes or the number of busses the district maintains. Through this project, the students would learn how they could influence the world around them by using their skills learned in school and by presenting their argument in a professional manner.

Middle-school students could also study the economic impact of school consolidation on their communities. In many instances, when communities lose a school, they lose businesses as well. Students could interview older community members from communities that lost schools about what businesses used to be in the community and explore possible connections with school consolidation. Students could make graphs to indicate the change in shopping patterns that have resulted. What the students are likely to find is that today, instead of shopping in the local community, people drive to a centrally located Wal-Mart or Ingles, often located near the consolidated high school or middle school. Students could ask how much gasoline and time driving to Wal-Mart consumes compared to shopping in the local community. This could lead to a study of the related economic impacts on those communities closest to and farthest from the consolidated schools.

\section{Grades 9-12}

In the high school years, much of the curriculum is predetermined to follow the Algebra I, Geometry, Algebra II, Trigonometry, Calculus route, or some variation therein. One way to incorporate these issues into the mathematics classroom involves establishing the values of the parameters used as weights with Dijkstra's algorithm.

For example, while the bus is setting on level ground a crude inclinometer (much like geometry students construct every year) consisting of a protractor and a weighted string could be fixed to the inside of the bus and set at zero degrees. The bus would then drive a route on uphill road segments where speed and inclination are as continuous as possible. All students could affix their inclinometers in view while seated to record observations at regular time intervals. A designated student could help in calling out bus speeds at the same time intervals. They could calculate an average of all student measurements for further accuracy with outliers disregarded before averaging. Students could determine percent decrease in bus speed due to percent grade using integer values and interpolation used for fractional percents of grade. As an alternative, the 
regression capabilities of a graphing calculator are useful to formulate an equation for percent decrease in speed as a function of percent road grade.

The students can also study how other road conditions such as paved versus unpaved and curvy versus straight impact the travel times of the busses. They could use this information to write letters to the local paper and to the regional government to work toward improving these roads as a method of improving the education of the students in that area.

The mathematics that students of this age are capable of engaging is more sophisticated as is their ability to debate and advocate. Many states involve high school students in their legislative bodies whereby bills are proposed and passed through democratic process and adopted as state policy. All of the ideas presented from previous grade strands could culminate in the formulation of a proposed bill that would treat the bussing issue from multiple perspectives. They could choose to tackle the big issue of school consolidation or propose solutions within the existing system. Either way, the students learn advocacy as a component of good citizenship and that they can make a difference for the local community.

\section{Other Post-Secondary}

While a large portion of the general population will not attend college, those who do often take a mathematics course entitled Finite Mathematics or Mathematics for the Liberal Arts. This course is usually a terminal mathematics course for students who will not be majoring in a science subject and is often taught as a dual credit course in high schools. One of the primary topics discussed in such a course is graph theory. In order to address the majority of the issues involved in rural school bussing, it would require only a minor change in the curriculum to include these issues when discussing topics in graph theory. This may occur either as a group project, or possibly as just another homework assignment by simplifying the problem down to something manageable.

The instructor could also use any of the ideas discussed for the previous age groups to engage their students in critical thinking and help them to work toward making a change to improve their rural community.

\section{Conclusion}

No matter what age and education level involved, learning and discussion can take place. It is through the education and cooperation of the local rural community that change will occur.

Finally, we must remember that while the issue of rural school bussing is important to the rural community, many other issues can and should be addressed in the mathematics classroom. We encourage all teachers in a rural setting to explore other topics of interest to their students and community and articulate the mathematical issues involved. By addressing issues of importance to rural communities in the mathematics classroom, we can improve the students' attitudes towards mathematics, help their parents see the relevance of the mathematics their children are learning while at the same time helping the rural community to become better informed and more capable of influencing the decisions that affect their lives. 


\section{References}

Chartrand, G., \& Oellermann, O. (1993). Applied and algorithmic graph theory. New York: McGraw-Hill.

Chen, D., Kallsen, H. A., Chen, H., \& Tseng, V. (1990). A bus routing system for rural school districts. Computers and. Industrial Engineering, 19(1-4) (Jan. 1990), 322-325.

Corberan, A., Fernandez, E., Laguna, M., \& Marti, R. (2002). Heuristic solutions to the problem of routing school buses with multiple objectives. Journal of the Operational Research Society, 53, 427-435.

Dewey, J. (1916). Democracy and education. New York: Macmillan.

DeYoung, A. (1995). The life and death of a rural American high school: Farewell Little Kanawha. New York, NY: Garland Publishing.

DeYoung, A., \& Howley, C. (1992). The political economy of rural school consolidation. Peabody Journal of Education, 67(4), 63-89.

Dunham, W. (1991). Journey through genius: The great theorems of mathematics. New York: Penguin Books.

Durkheim, E. (1961). Moral education. The Free Press.

Floyd, L. (1983). The impact of busing on student achievement. Lexington, KY: University of Kentucky.

Fox, M. (1996). Rural transportation as a daily constraint in students' lives. Rural Educator, 17(2), 22-27.

Gruenewald, D. (2003). The best of both worlds: A critical pedagogy of place, Educational Researcher, 32(4), 3-12.

Herbst, M., \& Herczyński, J. (2005). Is large more effective than small is beautiful? Size and performance of primary schools in Poland. Paper presented at the Global Conference on Education Research in Developing Countries in Prague, Czech Republic. Retrieved November 15, 2007 from http://www.cerge-ei.cz/pdf/gdn/RRCIV_37_paper_01.pdf

Howley, C. (1996). Compounding disadvantage: The effects of school and district size on student achievement in West Virginia. Journal of Research in Rural Education, 12(1), 25-32. Retrieved November 15, 2007, from http://www.acclaimmath.com/docs/jrre_archives/v12,n1,p25-32,Howley.pdf

Howley, C. (2000). An agenda for studying rural school busing. Journal of Research in Rural Education, 16(1), 51-58. Retrieved November 15, 2007, from http://www.acclaimmath.org/docs/jrre_archives/v16,n1,p51-58,Howley.pdf

Howley, C. (2001). The rural school bus ride in five states: A report to the rural school and community trust. Randolph, VT: Rural School and Community Trust.

Howley, C., \& Howley, A. (2001). Rural school busing. ERIC Digest. Retrieved November 15, 2007 from http://www.acclaim-math.org/docs/htmlpages/Rural\%20School\%20Busing.htm.

Howley, C., \& Howley, A. (2004). School size and the influence of socioeconomic status on student achievement: Confronting the threat of size bias in national data sets [Electronic version]. Education Policy Analysis Archives, 12(52).

Howley, C., Howley, A., \& Shamblen, S. (2001). Riding the school bus: A comparison of the rural and suburban experience in five states. Journal of Research in Rural Education, 17(1). Retrieved November 15, 2007, from http://www.acclaimmath.org/docs/jrre_archives/v17,n1,p41-63,Howley.pdf

Killeen, K., \& Sipple, J. (2000). School consolidation and transportation policy: An empirical and institutional analysis. Randolph, VT: Rural School and Community Trust.

Lu, Y., \& Tweeten, L. (1973). The impact of busing on student achievement [Electronic version]. . Growth and Change, 4(4), 44-46.

Lyson, T. A. (2002). What does a school mean to a community? Assessing the social and economic benefits to rural villages in New York. Journal of Research in Rural Education 17(3). Retrieved November 15, 2007, from http://www.acclaimmath.org/docs/jrre_archives/v17,n3,p131-137,Lyson.pdf

Mathews, D. (1996). Is there a public for public schools. Dayton, OH: Kettering Foundation Press. 
Messer, C. J., \& Pacelli, M. J. (1998). Development of an annunciation system for rural school bus operations. College Station, TX: Southwest Region University Transportation Center, Texas Transportation Institute.

Nygard, K. E., Summers, D. E., \& Wagner, R. E. (1982). Computer aided school bus routing for rural districts. Association for Educational Data Systems Journal, 17(4), 200-208.

Peshkin, A. (1978). Growing up American: Schooling and the survival of community. Chicago, IL: University of Chicago Press.

Ramage, W. R., \& Howley, A. (2003). Children's experiences of long bus rides: Parents' perspectives. Paper presented at the annual meeting of the American Educational Research Association, Chicago, IL.

Reeves, C. (2003). Implementing the No Child Left Behind Act: Implications for rural schools and districts. $\quad$ Retrieved November 15, 2007, from http://www.ncrel.org/policy/pubs/html/implicate/NCLB_PolicyBrief.pdf

Rhoulac, T. D., Rouphail, N., \& Tsai, J. C. (2000). Using global positioning systems to improve school bus routing and scheduling. Transportation Research Board Paper No. 01-3050. Retrieved November 15, 2007 from http://itre.ncsu.edu/STG/downloads/GPS.pdf

Spence, B. (2000a). Long school bus rides: Stealing the joy of childhood. Charleston, WV: Challenge West Virginia. Retrieved November 15, 2007, from http://www.wvcovenanthouse.org/challengewv/news/Bus.pdf

Spence, B. (2000b). Long school bus rides: Their effect of school budgets, family life, and student achievement. Charleston, WV: Appalachian Regional Education Laboratory.

Theobald, P., \& Nachtigal, P. (1995). Culture, community, and the promise of rural education. Phi Delta Kappan, 77(2), 132-135.

Tonnies, F. (1887/1957). Community and society. (C.P. Loomis, Trans.). Lansing, MI: Michigan State University Press.

U.S. Census Bureau (2006). 2006 American Community Survey. Washington DC: Census Bureau. Retrieved October 25, 2007 from http://factfinder.census.gov

Wheeler, E. \& Brawner, J. (2005). Discrete mathematics for teachers. Boston, MA: Houghton Mifflin Company.

Woodrum, A. (2004). State-mandated testing and cultural resistance in Appalachian schools: Competing values and expectations. Journal of Research in Rural Education, 19(1). Retrieved April 8, 2007, from http://www.umaine.edu/jrre/19-1.pdf

Zars, B. (1998). Long rides, tough hides: Enduring long school bus rides. Randolph, VT: Rural School and Community Trust.

Zoloth, B. S. (1976). The impact of busing on student achievement: Reanalysis. Growth and Change, 7(3), 43-47. 